\title{
Editor's Column
}

\section{$66 \sqrt{7}$}

HAT'S PMLA?" asks a character in a recent academic mystery novel, while another rests his feet on the "blue and white periodical"; a third solicitously but imperfectly explains, "Learned articles on English studies." Such unpardonable ignorance is mitigated when the reader of The Student Body, by J. S. Borthwick, takes into account that the principals in this exchange are a police sergeant, a sheriff's deputy, and a medical examiner and that earlier in the novel, by contrast, a newly appointed teaching fellow, reminding herself that she is now a serious scholar, feels slightly ill when she supposes she will have to try to write essays like the one called "The Dialectics of Movement in Keats's 'To Autumn."” Rare in any case is the journal, the scholarly journal in particular, that achieves a pinnacle of renown so lofty as to invite the homage of a satiric portrayal in a work of fiction, a gesture of immortalization that $P M L A$ had already received in David Lodge's Small World. Notoriety of another, perhaps more likely, order came to PMLA last March when a New York Times reporter, Richard Bernstein, under the headline "A Traditionalist Takes on Feminists over Shakespeare," picked up the polemic between Richard Levin and the group whose Forum letter protested the publication of his "Feminist Thematics and Shakespearean Tragedy" (Mar. 1988). Bernstein's lengthy account subsequently found its way into other newspapers, from the Trenton Times to the International Herald Tribune. Whether news to be taken seriously or a curiosity on a fictional coffee table, PMLA is not ignored. Potential contributors, aware of the public eye that so often lights on these pages, have not been ignoring $P M L A$ either.

A healthy increase in submissions over the past two years, with no decrease in the quality of the work or in the percentage accepted, has produced a concomitant increase in $P M L A$ 's backlog. Although financial strictures discourage unlimited growth-alas, an editor's ideal does not always correspond to administrative realities-PMLA has, in fact, become more corpulent, and its expansion has, so far, prevented any measurable delay in the rate of publication of the articles on hand. Contemplating this trove of papers waiting to be printed, the Editorial Board observed some happy coincidences: correspondences, both logical and unexpected, connecting groups of essays through chronology, geography, theme, or methodology. To take advantage of potentially fruitful dialogues among studies that had been submitted independently, the board decided to print these articles in successive clusters, each with a brief introduction by a board member. Unlike the special-topic features, designed to stimulate concretely focused submissions, the clusters are self-generated groupings that have been culled from the current stock of accepted articles. The first of these clusters appears in the present issue. Three important examinations of key authors and texts of British literature from the Victorian period stand in telling juxtaposition, and I thank George Levine for his presen- 
tation of the trio. The next number of $P M L A$ will gather five pieces in the Hispanic field, and future issues will bring a modern cluster, to be introduced by Richard Brodhead, and a cluster on readers and reading, with prefatory remarks by Constance Jordan. In conjunction, the related essays provide historical and critical insights over and above the statements they make as unique entities.

Another four contributions, of varied subject matter, serve to balance the present issue. The fare begins with an article that one referee termed "charmingly cheeky": Bruce Boehrer's "Renaissance Overeating: The Sad Case of Ben Jonson." This fresh reading of Jonson's verse in the light of his era's social values is a tempting new-historical combination of biography and criticism that uncovers tensions, instabilities, and contradictions in the play between obesity and poetry. Feasting of another sort informs "Clarissa and Ritual Cannibalism," Raymond Hilliard's ingenious examination of orality and victimization in Richardson's novel. As surprising as it is illuminating, this essay applies current anthropological and psychoanalytic theory to an eighteenthcentury text and raises important questions about narrative control and about the novel as a ritualized cultural institution. Clayton Koelb's close rhetorical analysis of Heinrich von Kleist's "Michael Kohlhaas" uncovers the implications of textuality and writing that hover beneath the surface of this short story. Koelb nuances the destructive and regenerative powers of reading and brings into harmony the text's confrontation between natural and supernatural levels that have struck earlier commentators as disparate. Finally, PMLA welcomes an essay focused on a South African writer and, along with him, on the entire debate over cultural value and social responsibility in his country today. With good reason, Debra Castillo uses Barthes's apprehensions of myth as the theoretical springboard for her study of postcolonialist discourse in Coetzee's first novel, Dusklands.

An essay in our series of contributions by honorary members and fellows of the MLA rounds out this issue. We are deeply grateful to Mario Vargas Llosa for having cooperated with us at a particularly busy time in his public career and for allowing $P M L A$ to publish an English version of his three-part rumination sparked by the writings of the contemporary Austrian philosopher Karl Popper. We are also indebted to Raymond L. Williams of the University of Colorado for his successful efforts to sustain communication between us and the Peruvian novelist. In a few compact pages Vargas Llosa provocatively ranges over deep and troubling issues: the nature of truth and its changing valences and the bearing that freedom and tolerance have on truth; the growth of a critical spirit and of individual responsibility that an open society produces; the recalcitrance of history, the threats that historicist constructs pose to freedom, and the proximity of history to fiction. These are matters that, in various contexts, all of us confront in our teaching and writing.

What part, if any, of the contents of this issue of $P M L A$ will be summarized and reviewed in a newspaper or analyzed and criticized in another academic journal or parodied in an as yet unborn novel I cannot predict. That the essays united here will, singly or collectively, in one medium or another, produce responses is certain. They will carry on the good name and the fame of our journal. Only in the unreal annals of fiction could someone possibly ask, "What's $P M L A$ ?" 